\title{
Antigen-specific $\mathrm{CD} 4^{+}$and $\mathrm{CD} 8^{+} \mathrm{T}$-cell responses in $\mathrm{PBMC}$ from pony mares immunized with either native or recombinant zona pellucida vaccines
}

C.J. Joonè ${ }^{a, *}$, M.L. Schulmanª, G.T. Fosgate ${ }^{a}$, T.A. Plagis ${ }^{b}$, J.E. Crafford', S.K. Gupta ${ }^{d}$, , H.J. Bertschinger ${ }^{\mathrm{e}}$

aDepartment of Production Animal Studies, Faculty of Veterinary Science, University of Pretoria, Old Soutpan Road, Onderstepoort, 0110, South Africa

bUtrecht University, Yalelaan 1112, 3584 CM Utrecht, The Netherlands

'Department of Veterinary Tropical Diseases, Faculty of Veterinary Science, University of Pretoria, Old Soutpan Road, Onderstepoort, 0110, South Africa

${ }^{\mathrm{d}}$ Reproductive Cell Biology Laboratory, National Institute of Immunology, Aruna Asaf Ali Marg, New Delhi, 110 067, India

eVeterinary Population Management Laboratory, Faculty of Veterinary Science, University of Pretoria, Old Soutpan Road, Onderstepoort, 0110, South Africa

*Corresponding author. Email: Carolynne.Joone@jcu.edu.au. Present address: College of Public Health, Medical and Veterinary Sciences, Division of Tropical Health and Medicine, James Cook University, 1 James Cook Drive, Townsville, Queensland, 4811, Australia

\section{Highlights}

- Cell-mediated immune response to zona pellucida-based vaccines was investigated using CFSE dilution and immunophenotyping.

- Significant anamnestic antigen-specific $\mathrm{CD} 4^{+}$and $\mathrm{CD} 8^{+} \mathrm{T}$-lymphocyte responses were detected.

- Data suggest that CTL may play a role in ovarian suppression observed during pZP immunocontraception in the mare.

- Further investigation into the role of CTL during zona pellucida-based immunocontraception is warranted. 


\section{Abstract}

Few studies have investigated the cell mediated immune response during zona pellucida-based immunocontraception, despite hypothesized cytotoxic T-cell involvement in ovarian dysfunction associated with these vaccines. This study aimed to investigate antigen-specific anamnestic responses of helper $\left(\mathrm{CD} 4^{+}\right)$and cytotoxic $\left(\mathrm{CD} 8^{+}\right)$T-lymphocytes in peripheral blood mononuclear cells (PBMC) isolated from pony mares before and after their treatment with native porcine zona pellucida (pZP), recombinant pZP3 and pZP4 antigens (reZP) or adjuvanted saline. Mares were randomly assigned to pZP, reZP and control groups ( $n=7$ per group). Treatments consisted of a primary vaccination or saline (V1; Day 0) incorporating Freund's modified complete adjuvant, followed by a single booster (V2; Day 35) incorporating Freund's incomplete adjuvant. Peripheral blood mononuclear cells were isolated and cryopreserved immediately prior to V1 (Day 0) and five weeks post V2 (Day 70). Relative proliferation of T-lymphocytes in response to pZP antigen was assessed using carboxyfluorescein diacetate succinimidyl ester dilution with immunophenotyping, analysed via flow cytometry. Significant pZP-specific CD4 ${ }^{+}$and $C D 8^{+}$T-lymphocyte responses were detected in PBMC isolated from mares treated with either pZP or reZP, in comparison to pretreatment samples. In the pZP group, but not the reZP group, $C D 8^{+} \mathrm{T}$-cell proliferation showed significant negative correlations to circulating progesterone, oestradiol and anti-Müllerian hormone levels. Results suggest that antigen-specific $\mathrm{CD} 8^{+} \mathrm{T}$-cells may play a role in ovarian suppression observed during pZP immunocontraception in this species.

Keywords: Immunocontraception; T-lymphocytes; Cell mediated immune response; Cytotoxic T-cells; Horse

\section{Introduction}

The zona pellucida (ZP), a glycoproteinaceous matrix surrounding the mammalian oocyte, is intricately involved in oocyte maturation, sperm-oocyte union and protection of the early embryo [1, 2]. The role of the ZP in reproduction, as well as its tissue-specific nature, have encouraged interest in the development of ZP glycoproteins-based vaccines as contraceptive agents [3, 4]. Around eighty mammalian species have been successfully contracepted with the native porcine ZP (pZP) vaccine, with pZP research in horses (Equus caballus) spanning nearly 30 years $[5,6]$. 
The primary mechanism of action of pZP in the mare is traditionally considered to be an antibodymediated interference with sperm-oocyte binding and, or fertilization [6, 7]. Disturbances in ovarian function have been reported in various species, including non-human primates [8], rabbits [9], sheep [10] and dogs [11]. Recently, two studies in mares documented ovarian suppression during pZP immunocontraception, stimulating renewed interest in the vaccine's mechanism of action [12, 13].

Several hypotheses regarding the cause of ovarian dysfunction detected during ZP-based immunocontraception have been advanced. Apart from individual species-based differences in immune responses [5], ovarian dysfunction may be induced by a particular adjuvant [14] or contamination of native pZP preparations with extra-ZP ovarian antigens [8]. Alternatively, cytotoxic T-lymphocytes (CTL, $\left.C D 8^{+}\right)$have been hypothesized to play a role $[1,15-18]$.

The current study investigated anmnestic cellular immune responses of peripheral blood mononuclear cells (PBMC) isolated from pony mares before and after their immunization with either pZP or a newly developed recombinant pZP3 and pZP4 (reZP) vaccine [19], with comparison to adjuvanted control mares. Relative proliferation of $\mathrm{CD} 4^{+}$and $\mathrm{CD} 8^{+} \mathrm{T}$-cells, in response to pZP antigen, was measured using carboxyfluorescein diacetate succinimidyl ester (CFSE) dilution, analysed by flow cytometry. Data were compared to antibody titres, serum oestradiol, progesterone and anti-Müllerian hormone (AMH) concentrations, ovarian volumes and pregnancy outcomes reported previously [13].

\section{Materials and Methods}

This study was approved by the University of Pretoria's Animal Ethics Committee (V051-13 and V004-14).

\subsection{Study design}

The study design and formulations of the pZP and reZP vaccines have been described previously [13]. Briefly, 21 pony mares aged between three and 14 years were randomly assigned to one of three study groups: pZP, reZP and controls ( $n=7$ per group). Treatments consisted of a primary vaccination (V1; Day 0) followed by a single booster (V2; Day 35). For the pZP group, V1 consisted of $100 \mu \mathrm{g}$ native pZP, prepared according to standard methods [6], emulsified with Freund's modified complete adjuvant (FMCA). The booster vaccination differed only in incorporating Freund's 
incomplete adjuvant (FIA) instead of FMCA. For the reZP group, V1 consisted of $250 \mu \mathrm{g}$ each of recombinant porcine ZP3 and ZP4 expressed by Escherichia coli, with promiscuous T-cell epitopes of either tetanus toxoid (TT) or bovine RNase (bRNase) respectively, emulsified with FMCA [19]. Similarly, FIA replaced FMCA for V2. For the control group, V1 and V2 consisted of sterile saline emulsified with FMCA and FIA respectively.

\subsection{Blood sampling for PBMC isolation and cryopreservation}

Blood samples were collected by jugular venipuncture into heparinised blood collection tubes, immediately prior to V1 (Day 0) and five weeks post V2 (Day 70). Peripheral blood mononuclear cells were isolated by standard histopaque density gradient centrifugation, cryopreserved and stored at $140^{\circ} \mathrm{C}$ until required.

\subsection{In vitro T-cell proliferation and immunophenotyping using flow cytometry}

Proliferation of T-cells in response to antigen was assessed using CFSE dilution, as described previously in humans [20]. Briefly, cryopreserved PBMCs were thawed, washed and stained with CFSE (Celltrace ${ }^{\mathrm{TM}}$ CFSE cell proliferation kit; Life Technologies, Fairland, South Africa) at a final concentration of $1 \mu \mathrm{M}$ for $10 \mathrm{~min}$ at $37^{\circ} \mathrm{C}$. Staining was quenched by the addition of five volumes of ice cold RPMI-1640 medium with 10\% foetal calf serum (FCS). After washing, cells were plated in triplicate in 24-well flat-bottom plates at a concentration of $1 \times 10^{6} \mathrm{cell} / \mathrm{s} / \mathrm{ml}$. Negative control, positive control and test wells received medium only, Concanavalin A (ConA, $2.5 \mu \mathrm{g} / \mathrm{ml}$; Sigma Aldrich, Johannesburg, South Africa) and pZP ( $2.5 \mathrm{\mu g} / \mathrm{ml}$; Trumpeter Farms and Veterinary Service, CA, USA), respectively. Cells were cultured in RPMI-1640 medium containing 5\% FCS, $1 \%$ penicillinstreptomycin and $1 \% \mathrm{~L}$-glutamine at $37^{\circ} \mathrm{C}$ with $5 \% \mathrm{CO}_{2}$ for five days. Cell counting was performed using the TC20 Automated Cell Counter (Bio-Rad, Hercules, CA, USA).

Prior to flow cytometry, cells were transferred to 96-well round-bottom plates at a concentration of $5 \times 10^{6}$ cells $/ \mathrm{ml}$, maintaining pairs of test wells and negative and positive control wells. Paired wells underwent staining for CD4 (mouse anti-horse CD4-RPE; Celtic Molecular Diagnostics, Mowbray, South Africa) and CD8 (mouse anti-horse CD8-phycoerythrin (RPE); Celtic Molecular Diagnostics), respectively. Cells were then permeabilized and fixed (Cytofix/Cytoperm ${ }^{\mathrm{TM}}$ Fixation/Permeabilization Kit; BD Biosciences, San Diego, CA, USA) followed by staining for CD3 (rat anti-human CD3-AlexaFluor 
647; Celtic Molecular Diagnostics). Data were acquired using the Accuri C6 with CSampler (BD Biosciences). Data acquisition was set to include 50,000 events within the lymphocyte population, identified based on forward (FSC) and side (SSC) scatter parameters. Computed compensation was applied prior to analysis using FlowJo v10 software (FlowJo; Ashland, OR, USA).

\subsection{Gating strategy and data analysis}

Events were sequentially gated to exclude debris and doublets, followed by gating of a low SSC, $C D 3^{+}$ population. The gated population was subsequently evaluated within a density plot of RPE (FL2) versus CFSE (FL1). Gating of $\mathrm{CD} 4^{+}$or $\mathrm{CD} 8^{+}$populations accommodated the slight oblique between RPE-positive and negative cells when assessed in combination with CFSE (Supplementary Fig. 1). Finally, proliferated versus non-proliferated populations were identified within a histogram of CFSE fluorescence.

Cell proliferation was evaluated as a percentage of the maximal (positive control), corrected for nonspecific proliferation (negative control), using the following formula:

Relative proliferation $(\%)=(\Delta$ geometric mean test well $-\Delta$ geometric mean negative control well) $/$ ( $\Delta$ geometric mean positive control - $\Delta$ geometric mean negative control) $\times 100 \%$, where $\Delta$ geometric mean = geometric mean (non-proliferated cells) - geometric mean (total cells) [20] .

Correlations were performed between collected data and antibody titres, circulating progesterone, oestradiol and AMH concentrations, mean ovarian volumes and pregnancy outcomes reported previously [13].

\subsection{Statistics}

The normality assumption for quantitative data was assessed by describing the distributions using descriptive statistics, plotting histograms, and performing the Anderson-Darling test in commercial software (MINITAB Statistical Software, Release 13.32, Minitab Inc, State College, Pennsylvania, USA). Data were descriptively presented using line plots created in the ggplot2 package [21] within $\mathrm{R}$ [22]. Quantitative data were compared between day 0 and day 70 using Wilcoxon signed-rank tests. Quantitative data prior to vaccination (day 0 ) were subtracted from post vaccination (day 63 for antibody titres, day 105 for AMH and days 63 through 105 for all other outcomes) values for 
further statistical analysis. Calculated differences were compared among treatment groups using Kruskal-Wallis tests followed by post hoc pairwise Mann-Whitney $U$ tests incorporating Bonferroni correction of $\mathrm{P}$ values. The correlations between measurements were estimated using Spearman's rho. Data analysis was performed using commercially available software (IBM SPSS Statistics for Windows, Version 25, IBM Corp, Armonk, NY, USA) and results interpreted at the 5\% level of significance.

\section{Results}

\subsection{Antigen-specific $C D 4^{+}$and $C D 8^{+} T$-cell responses}

Purified PBMC isolated from mares immunized with pZP or reZP showed significantly increased antigen-specific $\mathrm{CD} 4^{+}$and $\mathrm{CD} 8^{+} \mathrm{T}$-cell responses in comparison to pre-treatment values, whereas control mares treated with adjuvanted saline showed no difference in antigen-specific $\mathrm{CD} 4^{+}$or $\mathrm{CD} 8^{+}$ T-cell responses between time points (Table 1). Compared across groups, proliferation of $\mathrm{CD}^{+} \mathrm{T}^{\mathrm{T}}$ cells in the reZP group was significantly different to controls, with the pZP group demonstrating an intermediate effect not different to either the reZP or control groups. Relative proliferation of $\mathrm{CD} 8^{+}$ T-cells showed a similar pattern of response (Table 1). Typical profiles of $\mathrm{CD} 4^{+} \mathrm{T}$-cell proliferation from representative mares in the PZP- and reZP-immunized groups are shown in Figures 1 and 2, respectively. Figures 3 and 4 show typical profiles of $C D 8^{+} T$-cell proliferation from representative mares in the PZP- and reZP-immunized groups, respectively.

\subsection{Correlations between immunological data and clinical findings}

A summary of changes in immunological measurements and clinical findings, including serum oestradiol, progesterone and AMH levels and mean ovarian volumes, pre- (day 0 ) and posttreatment (day $63 / 70$ or day 105 , or days 63 through 105 , depending on the availability of data and the points at which maximal responses were observed) is provided in Supplementary Table 1. 
Table 1. Comparison of the relative proliferation of $C D 4^{+}$and $C D 8^{+}$T-cells in response to porcine zona pellucida (pZP) antigen in PBMC isolated from mares treated with either native pZP ( $n=7)$, recombinant pZP3 and pZP4 (reZP; $n=7$ ) or adjuvanted saline (controls; $n=7)$.

\begin{tabular}{|c|c|c|c|c|c|}
\hline \multirow[b]{2}{*}{ Variable } & \multirow[b]{2}{*}{ Day } & \multicolumn{3}{|l|}{ Treatment group } & \multirow[b]{2}{*}{$\begin{array}{l}\mathrm{P} \\
\text { value* }\end{array}$} \\
\hline & & $\begin{array}{l}\text { pZP } \\
\text { Median (range) }\end{array}$ & $\begin{array}{l}\text { reZP } \\
\text { Median (range) }\end{array}$ & $\begin{array}{l}\text { Control } \\
\text { Median (range) }\end{array}$ & \\
\hline \multirow[t]{3}{*}{$\mathrm{CD}^{+} \mathrm{CD}^{+}$} & $\mathrm{d} 0$ & $5.44(-8.36,10.77)$ & $3.52(1.01,5.18)$ & $8.63(-12.57,10.64)$ & 0.387 \\
\hline & d 70 & $11.06^{a, b}(-3.30,35.27)$ & $35.89^{a}(11.11,52.01)$ & $1.99^{\mathrm{b}}(-21.32,15.20)$ & 0.005 \\
\hline & $\mathrm{P}$ valuet & 0.018 & 0.018 & 0.499 & \\
\hline \multirow[t]{3}{*}{$\mathrm{CD}^{+}{ }^{\mathrm{CD}} 8^{+}$} & d 0 & $1.77(-1.97,2.86)$ & $0.62(-10.82,8.08)$ & $0.86(-5.21,5.84)$ & 0.985 \\
\hline & $\mathrm{d} 70$ & $5.58^{\mathrm{a}, \mathrm{b}}(1.85,27.12)$ & $23.50^{\mathrm{a}}(8.24,33.47)$ & $1.62^{b}(-0.88,8.26)$ & 0.003 \\
\hline & P valuet & 0.028 & 0.018 & 0.398 & \\
\hline
\end{tabular}

*Based on Kruskal-Wallis tests comparing values among treatment groups. Medians without superscripts in common were significantly different $(\mathrm{P}<0.05)$ after post hoc pairwise Mann-Whitney $U$ tests incorporating Bonferroni correction of $P$ values.

†Based on Wilcoxon signed-rank tests comparing day 0 and day 70 responses. 
a)

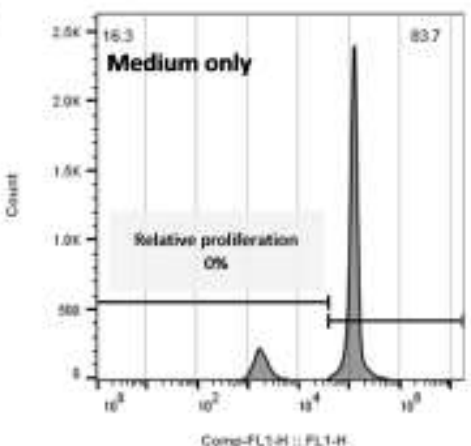

b)

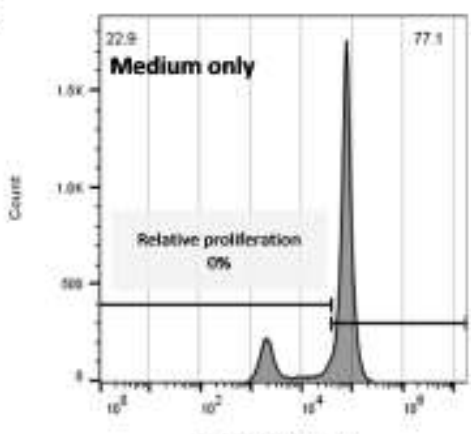

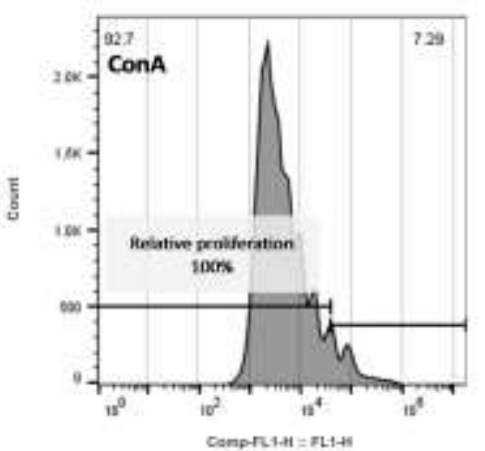
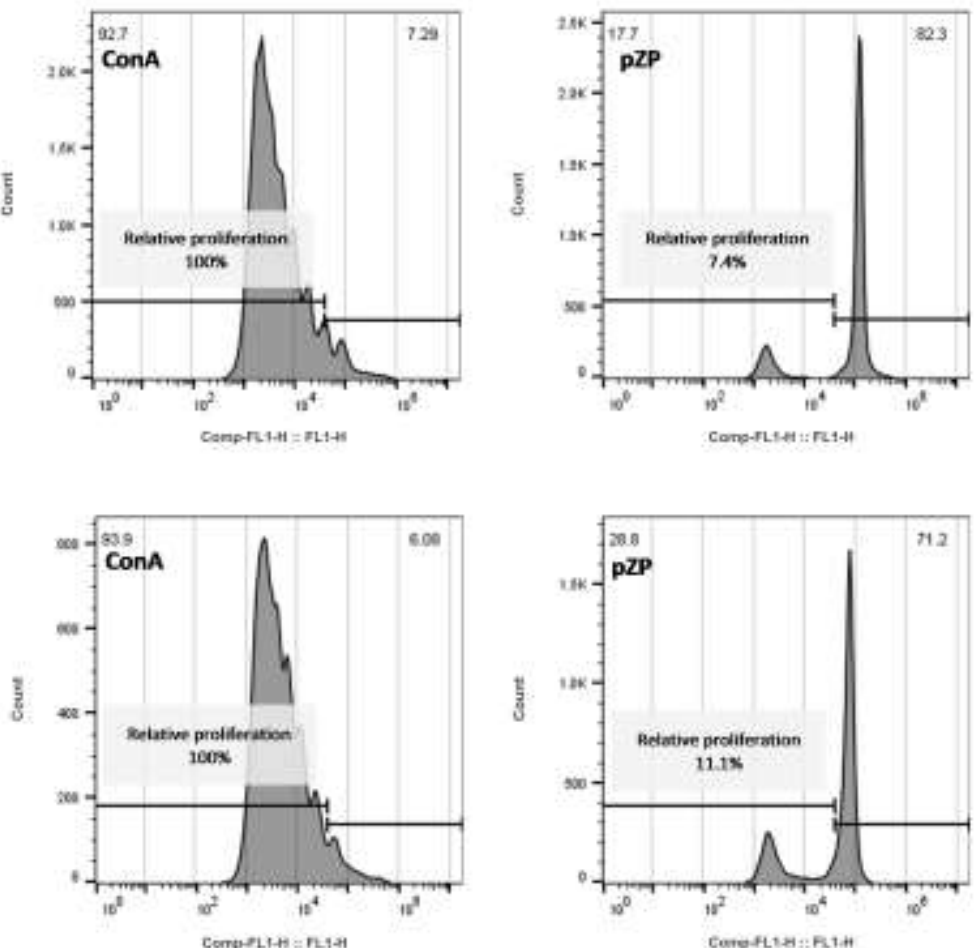

Fig. 1. Proliferation of $\mathrm{CD} 4^{+} \mathrm{T}$-cells from a representative mare in the pZP group, in response to medium only, ConA and porcine zona pellucida (pZP) antigen respectively, at two time points: a) Day 0 and b) Day 70.

a)

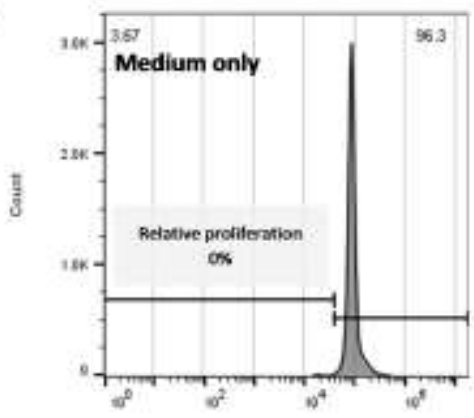

b)

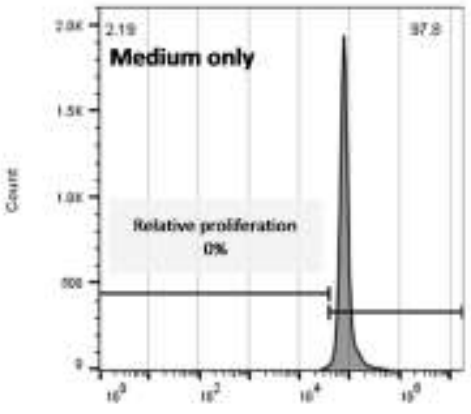

Compeith: Fis

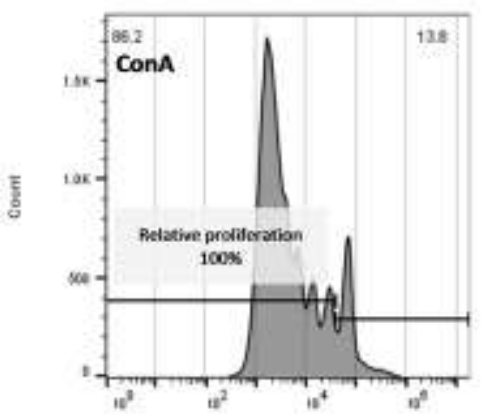

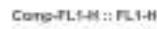

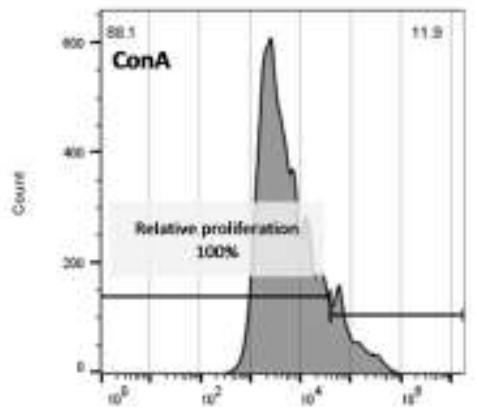

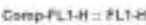

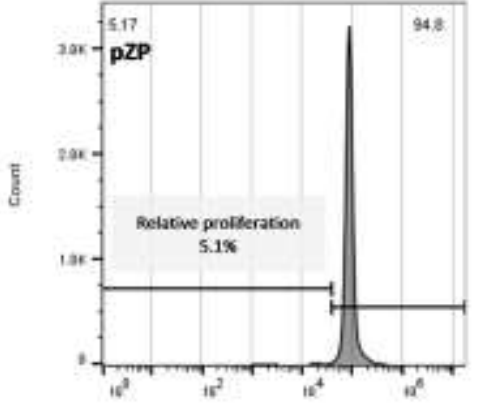

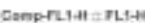

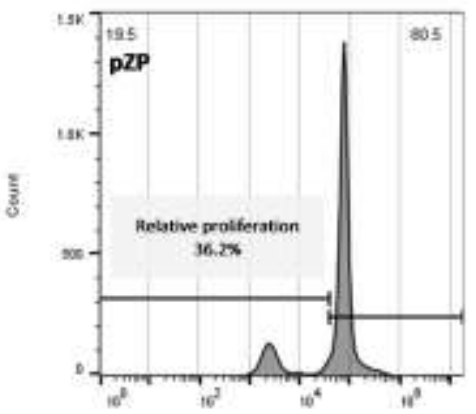

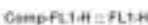

Fig. 2. Proliferation of $\mathrm{CD} 4^{+} \mathrm{T}$-cells from a representative mare in the reZP group in response to medium only, ConA and porcine zona pellucida (pZP) antigen respectively, at two time points: a) Day 0 and b) Day 70. 
a)

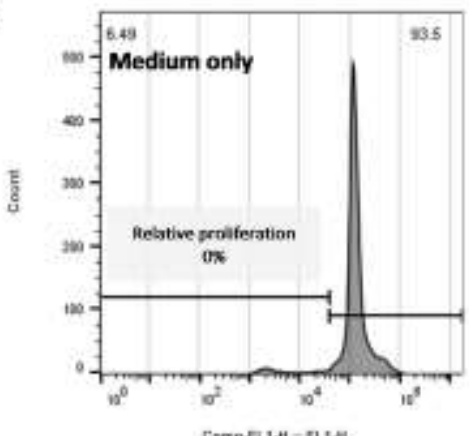

b)

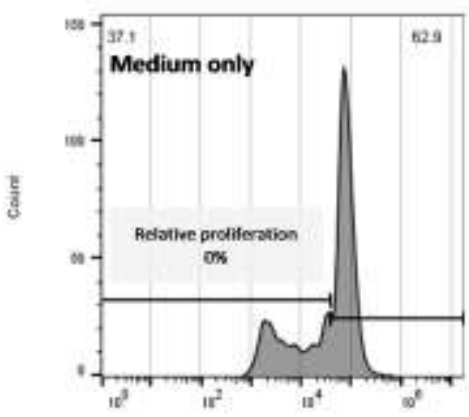

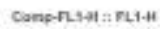

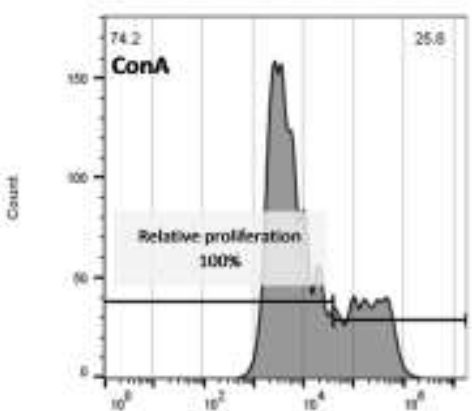

Congfltat RLAt

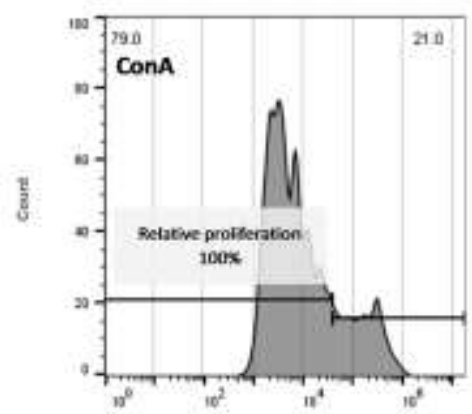

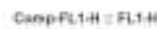

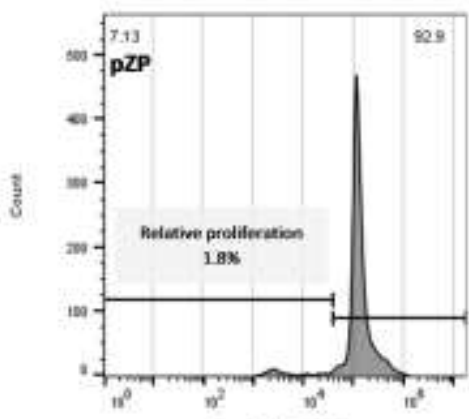

Camertith Fltal

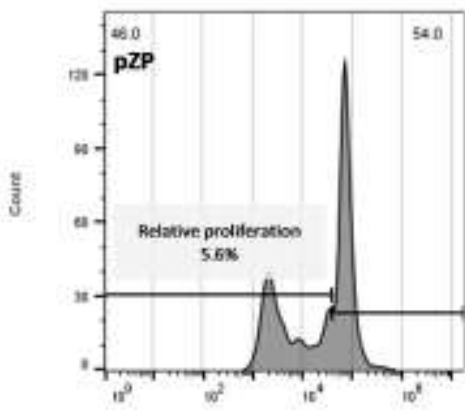

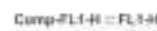

Fig. 3. Proliferation of $\mathrm{CD} 8^{+} \mathrm{T}$-cells from a representative mare in the pZP group in response to medium only, ConA and porcine zona pellucida (pZP) antigen respectively, at two time points: a) Day 0 and b) Day 70.

a)

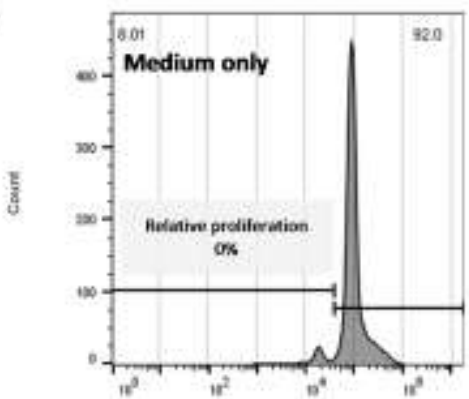

b)

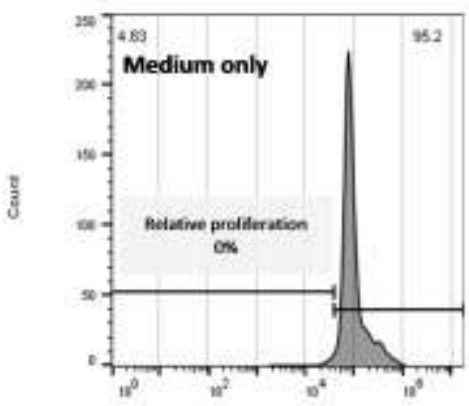

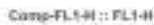

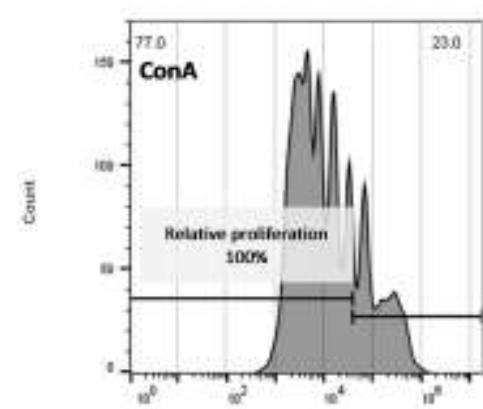

Compert te : P.1.

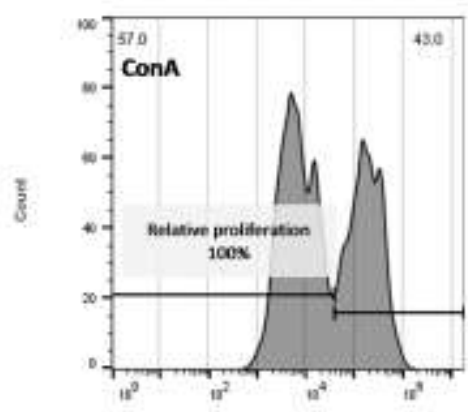

Coesfis.

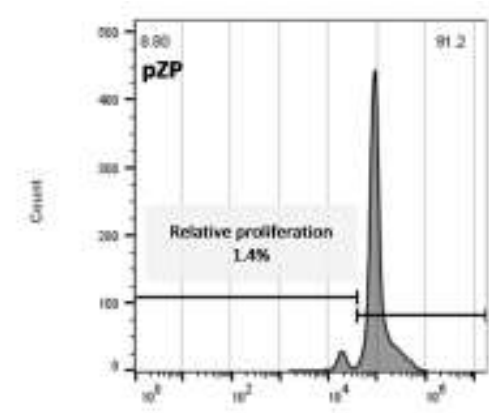

Camperstat $=\mathrm{FLCH}$

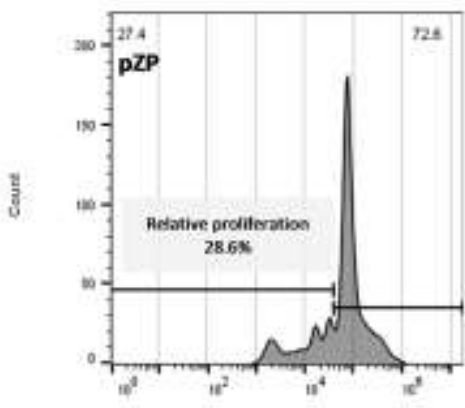

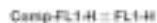

Fig. 4. Proliferation of $\mathrm{CD} 8^{+} \mathrm{T}$-cells from a representative mare in the reZP group in response to medium only, ConA and porcine zona pellucida (pZP) antigen respectively, at two time points: a) Day 0 and b) Day 70. 
Table 2. Correlations between immunological measurements and reproductive data recorded in mares treated with either native pZP ( $\mathrm{n}=7$ ), recombinant pZP3 and pZP4 (reZP; $n=7$ ) or adjuvanted saline (controls; $n=7$ ). Data were collected at the day of vaccination (Day 0 ) and at least four weeks post booster (Day 63).

\begin{tabular}{|c|c|c|c|c|}
\hline Variable 1 & Variable 2 & Sub-group & $\mathbf{n}$ & $\begin{array}{c}\text { Spearman's rho ( } P \\
\text { value) }\end{array}$ \\
\hline \multirow[t]{6}{*}{ Antibody PP } & $\mathrm{CD}^{+} \mathrm{CD}^{+} \mathrm{RP}$ & pZP and reZP treated & 28 & $0.484(0.009)$ \\
\hline & $\mathrm{CD}^{+} \mathrm{CD}^{+} \mathrm{RP}$ & pZP and reZP treated & 28 & $0.621(<0.001)$ \\
\hline & $\mathrm{AMH}$ & pZP and reZP treated & 28 & $-0.660(<0.001)$ \\
\hline & Oestradiol & pZP and reZP treated & 28 & $-0.678(<0.001)$ \\
\hline & Progesterone & pZP and reZP treated & 28 & $-0.374(0.050)$ \\
\hline & Mean ovarian volume & pZP and reZP treated & 28 & $-0.308(0.111)$ \\
\hline \multirow[t]{5}{*}{$\mathrm{CD}^{+} \mathrm{CD}^{+} \mathrm{RP}$} & $\mathrm{CD}^{+} \mathrm{CD}^{+} \mathrm{RP}$ & pZP and reZP treated & 28 & $0.709(<0.001)$ \\
\hline & $\mathrm{AMH}$ & pZP and reZP treated & 28 & $-0.378(0.047)$ \\
\hline & Oestradiol & pZP and reZP treated & 28 & $-0.271(0.164)$ \\
\hline & Progesterone & pZP and reZP treated & 28 & $-0.099(0.618)$ \\
\hline & Mean ovarian volume & pZP and reZP treated & 28 & $0.138(0.482)$ \\
\hline \multirow[t]{4}{*}{$\mathrm{CD}^{+} \mathrm{CD}^{+}{ }^{\mathrm{RP}}$} & $\mathrm{AMH}$ & pZP and reZP treated & 28 & $-0.395(0.038)$ \\
\hline & Oestradiol & pZP and reZP treated & 28 & $-0.564(0.002)$ \\
\hline & Progesterone & pZP and reZP treated & 28 & $-0.044(0.825)$ \\
\hline & Mean ovarian volume & pZP and reZP treated & 28 & $-0.041(0.838)$ \\
\hline \multirow[t]{4}{*}{ Antibody PP } & $\mathrm{AMH}$ & pZP treated & 14 & $-0.767(0.001)$ \\
\hline & Oestradiol & pZP treated & 14 & $-0.846(<0.001)$ \\
\hline & Progesterone & pZP treated & 14 & $-0.569(0.034)$ \\
\hline & Mean ovarian volume & pZP treated & 14 & $-0.565(0.035)$ \\
\hline \multirow[t]{4}{*}{$\mathrm{CD}^{+}{ }^{+} \mathrm{CD} 4^{+} \mathrm{RP}$} & $\mathrm{AMH}$ & pZP treated & 14 & $-0.415(0.140)$ \\
\hline & Oestradiol & pZP treated & 14 & $-0.244(0.401)$ \\
\hline & Progesterone & pZP treated & 14 & $-0.253(0.383)$ \\
\hline & Mean ovarian volume & pZP treated & 14 & $-0.314(0.274)$ \\
\hline \multirow[t]{2}{*}{$\mathrm{CD}^{+} \mathrm{CD}^{+} \mathrm{RP}$} & $\mathrm{AMH}$ & pZP treated & 14 & $-0.603(0.022)$ \\
\hline & Oestradiol & pZP treated & 14 & $-0.670(0.009)$ \\
\hline
\end{tabular}




\begin{tabular}{lllrr}
\hline & Progesterone & pZP treated & 14 & $-0.587(0.027)$ \\
Antibody PP & pean ovarian volume & pZP treated & 14 & $-0.270(0.350)$ \\
& AMH & reZP treated & 14 & $-0.295(0.306)$ \\
& Oestradiol & reZP treated & 14 & $-0.411(0.144)$ \\
& Progesterone & reZP treated & 14 & $-0.143(0.626)$ \\
$\mathrm{CD}^{+} \mathrm{CD}^{+} \mathrm{RP}$ & Mean ovarian volume & reZP treated & 14 & $0.095(0.748)$ \\
& & & \\
& AMH & reZP treated & 14 & $-0.451(0.106)$ \\
& Oestradiol & reZP treated & 14 & $-0.380(0.180)$ \\
& Progesterone & reZP treated & 14 & $-0.213(0.464)$ \\
$\mathrm{CD}^{+} \mathrm{CD} 8^{+} \mathrm{RP}$ & Mean ovarian volume & reZP treated & 14 & $0.323(0.260)$ \\
& & & & \\
& AMH & reZP treated & 14 & $-0.394(0.164)$ \\
& Oestradiol & reZP treated & 14 & $-0.530(0.051)$ \\
& Progesterone & reZP treated & 14 & $0.134(0.648)$ \\
& Mean ovarian volume & reZP treated & 14 & $-0.055(0.852)$ \\
\hline
\end{tabular}

$\mathrm{PP}=$ proportion positivity. $\mathrm{RP}=$ relative proliferation. $\mathrm{AMH}=$ anti-Müllerian hormone. 
Correlations between immunological and clinical data were performed with the treatment groups ( $p Z P$ and reZP) combined. Significant positive correlations were observed between antigen-specific $\mathrm{CD}^{+}$and $\mathrm{CD} 8^{+} \mathrm{T}$-cell responses, and antibody titres. Similarly, antigen-specific $\mathrm{CD} 4^{+}$and $\mathrm{CD} 8^{+} \mathrm{T}$-cell responses showed a strong positive correlation $(P<0.001)$ within this dataset. While AMH concentrations showed a significant negative correlation to both $\mathrm{CD} 4^{+}$and $\mathrm{CD} 8^{+} \mathrm{T}$-cell proliferation, oestradiol values showed a strong negative correlation to $C D 8^{+} T$-cell proliferation only $(P=0.002$; Table 2).

Correlations were also performed within each treatment group alone. In pZP-treated mares, $\mathrm{CD} 4^{+} \mathrm{T}$ cell proliferation showed no significant correlations to any of the reproductive variables assessed. However, $\mathrm{CD} 8^{+} \mathrm{T}$-cell proliferation showed significant negative correlations to $\mathrm{AMH}$, oestradiol and progesterone levels. In reZP-treated mares, no correlations between $\mathrm{CD} 4^{+}$or $\mathrm{CD} 8^{+} \mathrm{T}$-cell proliferation and reproductive variables were significant (Table 2).

Figure 5 illustrates anti-ZP antibody responses in treated and control mares pre-and post-treatment, with fertile versus infertile individuals identified. Figures 6 and 7 illustrate $C D 4^{+}$and $C D 8^{+} T$-cell proliferative responses respectively, in treated and control mares pre-and post-treatment, with fertile versus infertile individuals identified.

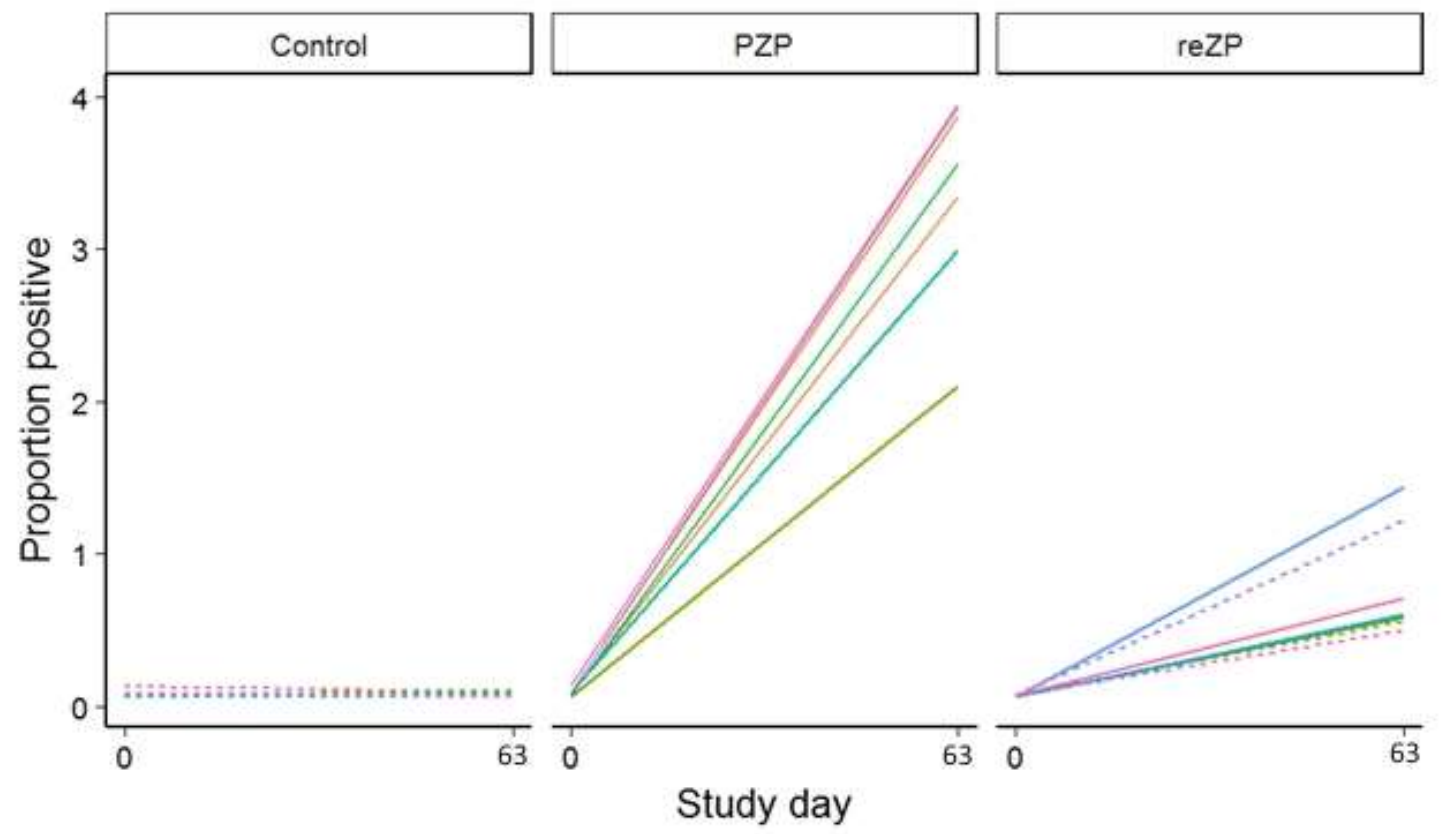

Fig. 5. Descriptive presentation of zona pellucida antibody responses in mares treated with either native pZP $(n=7)$, recombinant pZP3 and pZP4 (reZP; $n=7$ ) or adjuvanted saline (control; $n=7)$. Solid lines indicate responses from mares that did not conceive during the study. 


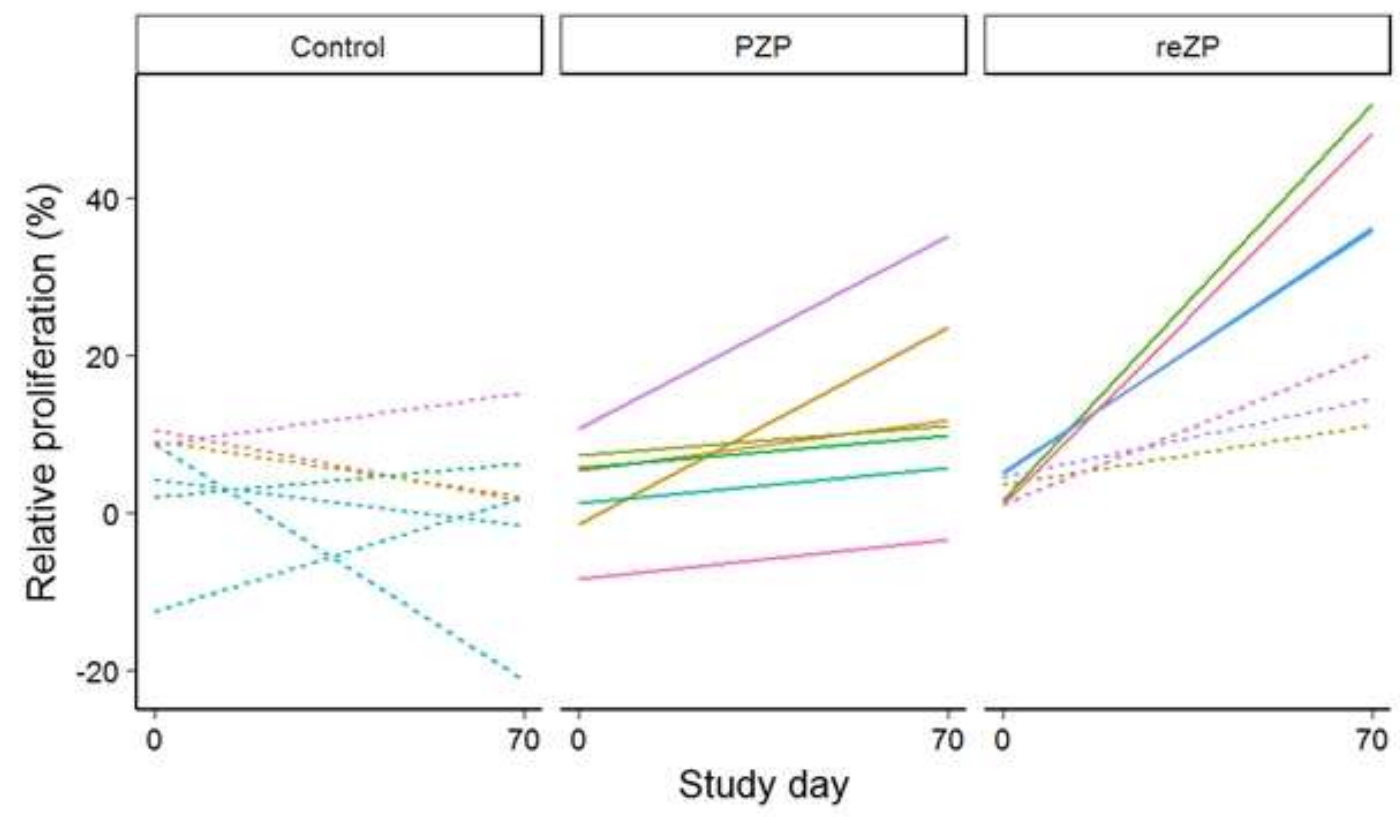

Fig. 6. Descriptive presentation of antigen-specific $\mathrm{CD} 4^{+} \mathrm{T}$-cell relative proliferation for mares treated with either native pZP $(n=7)$, recombinant pZP3 and pZP4 (reZP; $n=7)$ or adjuvanted saline (control; $n=7)$. Solid lines indicate responses from mares that did not conceive during the study.

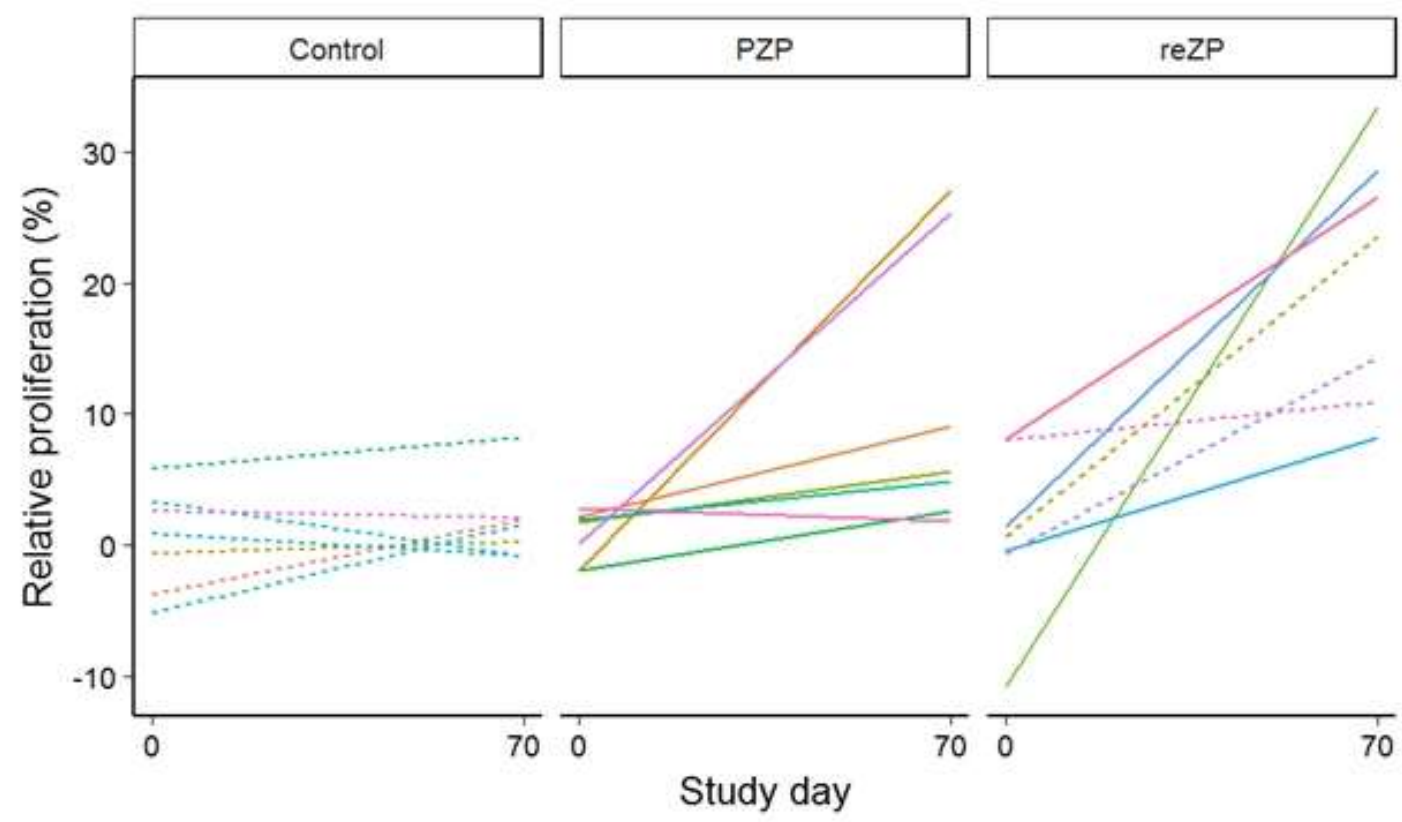

Fig. 7. Descriptive presentation of antigen-specific $\mathrm{CD} 8^{+} \mathrm{T}$-cell relative proliferation for mares treated with either native pZP $(n=7)$, recombinant pZP3 and pZP4 (reZP; $n=7)$ or adjuvanted saline (control; $n=7)$. Solid lines indicate responses from mares that did not conceive during the study. 


\section{Discussion}

The current study describes immunophenotyped in vitro T-cell responses to pZP antigen in PBMC isolated from mares vaccinated with pZP, reZP or saline (controls), analysed using CFSE dilution and flow cytometry. Tritiated thymidine uptake, measured using scintillation counting, has previously been employed to assess T-cell proliferative responses following ZP-based immunization in mice [19, $23,24]$ and cynomolgus macaques [23]. Phenotyping of T-cells was not a feature of these studies.

In the current study, significant $\mathrm{CD} 4^{+} \mathrm{T}$-cell responses were detected in response to pZP antigen by PBMC from both pZP- and reZP-immunized mares post treatment. Given the association between $\mathrm{CD}^{+} \mathrm{T}$-helper cells and the production of antibodies by plasma cells, this finding correlates with the anti-ZP antibody responses detected in both of these treatment groups [13]. The role of CD4+ $\mathrm{T}$-cells in the development of oophoritis during ZP-based immunocontraception has been investigated in mice. Adoptive transfer of ZP-specific CD4 ${ }^{+} \mathrm{T}$-cells, without associated antibodies, was found to induce significant levels of oophoritis [25]. A subsequent study demonstrated that oophoritis induced by $\mathrm{CD}^{+}{ }^{+} \mathrm{T}$-cells alone targeted the interstitial tissues of the ovary, including degenerate follicles but sparing developing follicles, and ovarian function was maintained. Interestingly, the copresence of ZP-specific antibodies and ZP-specific $\mathrm{CD} 4^{+} \mathrm{T}$-cells redirected the inflammatory response towards developing follicles, causing follicle ablation and culminating in ovarian atrophy [26].

Significant proliferation of CTL (CD8 ${ }^{+}$T-cells) was also detected in stimulated PBMC from pZP and reZP-immunized mares. These findings suggest ZP antigen uptake via an exogenous (non-classical) pathway for presentation by $\mathrm{MHCl}$ and subsequent CTL stimulation [27]. Few studies have investigated the role of CTL within the immune response to ZP-based vaccines. O'Leary et al. [28] demonstrated the presence of $\mathrm{CD} 4^{+}$and $\mathrm{CD} 8^{+} \mathrm{T}$-cells in ovarian sections derived from mice immunized with a recombinant murine cytomegalovirus engineered to express murine ZP3. However, the presentation of antigen via viral infection provides a direct link to the classical pathway to CTL stimulation via $\mathrm{MHCl}$, and need not be representative of immunization with pZP or reZP.

Interestingly, both $\mathrm{CD}_{4}^{+}$and $\mathrm{CD} 8^{+}$antigen-specific T-cell proliferation was greater in reZP- than pZPtreated mares. This finding contrasts to previously reported findings of lower antibody titres and weaker evidence of ovarian suppression and contraception in reZP- than pZP-treated mares [12]. Conjugation of recombinant pZP3 and pZP4 (reZP) to promiscuous T-cell epitopes of tetanus toxoid (TT) and bovine RNase (bRNase), respectively, aimed to enhance the immune response to these antigens. As T-cell proliferation in the current study was performed using native pZP as the test 
antigen, it is likely that proliferated $\mathrm{CD} 4^{+}$cells were ZP-specific rather than active against promiscuous T-cell epitopes of TT or bRNase. Further reasons for increased but seemingly futile cellmediated immune responses to reZP in comparison to pZP are speculative. Differences in the particulate nature of these vaccines, such as solubility or levels of aggregation, may influence antigen uptake by APC's and subsequent $C D 4^{+}$and $C D 8^{+}$T-cell stimulation [29]. Similarly, differences in the quaternary structures of recombinant versus native ZP proteins, influenced by their respective levels and patterns of glycosylation, may affect both B- and T-cell immune responses. Alternatively, pZP treatment may induce increased regulatory T-cells in comparison to reZP treatment, diminishing the cell mediated immune response within the former treatment group [30].

Comparisons between antigen specific T-cell responses and previously reported clinical findings aimed to shed more light on the effects of the measured T-cell responses. Within pZP treated mares, $\mathrm{CD}^{+} \mathrm{T}$-cell proliferation showed no significant correlations to either AMH, oestradiol or progesterone values, or mean ovarian volumes, despite significant to highly significant correlations between these clinical parameters and antibody titres. In contrast, $C D 8^{+} \mathrm{T}$-cell responses showed significant correlations to serum AMH, oestradiol and progesterone levels. Although further research is warranted, these findings suggest that $C D 8^{+} T$-cells may play a role in the suppression of ovarian function during zona pellucida-based immunocontraception in this species.

Within the reZP group, no correlations between $\mathrm{CD} 4^{+}$and $\mathrm{CD} 8^{+} \mathrm{T}$-cell responses and recorded clinical data were significant, although the correlation between $\mathrm{CD} 8^{+} \mathrm{T}$-cell proliferation and serum oestradiol levels approached significance $(P=0.051)$. Together with reported pregnancy outcomes in this group ( $57 \%$ versus $100 \%$ and $0 \%$ in the control and pZP groups respectively ), these findings suggest that the overt $\mathrm{CD} 4^{+}$and $\mathrm{CD} 8^{+} \mathrm{T}$-cell responses within the reZP group included components not directly responsible for ovarian suppression and,or contraceptive efficacy. Interestingly, descriptive presentations of the immunological responses within the reZP group suggest that infertile mares tended to exhibit more pronounced $C D 4^{+}$and $C D 8^{+}$T-cell responses (Figs. 6 and 7).

In pZP-immunized mares, it is likely that CTL are also generated against pZP2, a component not present in the reZP vaccine. In addition, contamination of the native pZP vaccine by non-ZP ovarian antigens, a feature wholly avoided by synthetic vaccines, could further differentiate the CTL responses. The role of immune responses to PZP2 in the pathogenesis of ovarian dysfunction is currently unclear, with few relevant reports available. Immunization of the female bonnet monkey (Macaca radiata) with E. coli-expressed recombinant bonnet monkey ZP2 conjugated with diphtheria toxoid led to inhibition of fertility associated with ovarian pathology [31]. In contrast, immunization of female mice with recombinant mouse ZP2 corresponding to amino acid residues 
35-637 led to inhibition of fertility without ovarian pathology, although the absence of ovarian pathology may have been mice strain-specific [32]. The role of extra-ZP ovarian contaminants in the pathogenesis of ovarian dysfunction during ZP-based immunocontraception is controversial (reviewed in [33]). It is unclear from the present study whether CTL generated against PZP2 or extraZP ovarian antigens, in pZP-immunized mares but not reZP-immunized mares, played a role in the pathogenesis of ovarian dysfunction seen in pZP- but not reZP-treated mares. Further studies of Tcell proliferative responses against specific antigenic constituents of pZP are warranted.

\section{Conclusion}

The current study demonstrates significant antigen-specific $\mathrm{CD} 4^{+}$and $\mathrm{CD} 8^{+}$anamnestic T-cell responses in PZP- and reZP-immunized pony mares, analysed via CFSE dilution and flow cytometry. Results suggest that $\mathrm{CD} 8^{+} \mathrm{T}$-cells may play a role in ovarian suppression associated with pZP immunocontraception in the horse.

\section{Acknowledgements}

This work was supported by the Technology Innovation Agency, South Africa (TAHC12 - 00042).

\section{Authors' declaration of interests}

No competing interests to declare.

\section{References}

[1] Prasad S, Skinner S, Carino C, Wang N, Cartwright J, Dunbar B. Structure and function of the proteins of the mammalian zona pellucida. Cells Tissues Organs 1999;166:148-64.

[2] Conner S, Lefievre L, Hughes D, Barratt C. Cracking the egg: increased complexity in the zona pellucida. Hum Reprod 2005;20:1148-52.

[3] Shivers C, Dudkiewicz A, Franklin L, Fussell E. Inhibition of sperm-egg interaction by specific antibody. Science 1972;178:1211-3. 
[4] Gupta SK, Shrestha A, Minhas V. Milestones in contraceptive vaccines development and hurdles in their application. Hum Vaccin Immunother 2014;10:911-25.

[5] Kirkpatrick JF, Rowan A, Lamberski N, Wallace R, Frank K, Lyda R. The practical side of immunocontraception: zona proteins and wildlife. J Reprod Immunol 2009;83:151-7.

[6] Liu IK, Bernoco M, Feldman M. Contraception in mares heteroimmunized with pig zonae pellucidae. J Reprod Fert 1989;85:19-29.

[7] Barber MR, Fayrer-Hosken RA. Possible mechanisms of mammalian immunocontraception. J Reprod Immunol 2000;46:103-24.

[8] Gulyas BJ, Gwatkin RB, Yuan LC. Active immunization of cynomolgus monkeys (Macaca fascicularis) with porcine zonae pellucidae. Gamete Res 1983;7:299-307.

[9] Skinner S, Mills T, Kirchick H, Dunbar B. Immunization with zona pellucida proteins results in abnormal ovarian follicular differentiation and inhibition of gonadotropin-induced steroid secretion. Endocrinology 1984;115:2418-32.

[10] Stoops MA, Liu IKM, Shideler SE, Lasley BL, Fayrer-Hosken RA, Benirschke K, et al. Effect of porcine zonae pellucidae immunisation on ovarian follicular development and endocrine function in domestic ewes (Ovis aries). Reprod Fert Develop 2006;18:667-76.

[11] Mahi-Brown C, Yanagimachi R, Hoffman J, Huang T. Fertility control in the bitch by active immunization with porcine zonae pellucidae: use of different adjuvants and patterns of estradiol and progesterone levels in estrous cycles. Biol Reprod 1985;32:761-72.

[12] Bechert U, Bartell J, Kutzler M, Menino A, Bildfell R, Anderson M, et al. Effects of two porcine zona pellucida immunocontraceptive vaccines on ovarian activity in horses. J Wildlife Manage 2013;77:1386-400.

[13] Joonè CJ, Bertschinger HJ, Gupta SK, Fosgate GT, Arukha AP, Minhas V, et al. Ovarian function and pregnancy outcome in pony mares following immunocontraception with native and recombinant porcine zona pellucida vaccines. Equine Vet J 2017;49:189-95.

[14] Upadhyay SN, Thillaikoothan P, Bamezai A, Jayaraman S, Talwar GP. Role of adjuvants in inhibitory influence of immunization with porcine zona pellucida antigen (ZP-3) on ovarian folliculogenesis in bonnet monkeys: a morphological study. Biol Reprod 1989;41:665-73.

[15] Bradley MP, Eade J, Penhale J, Bird P. Vaccines for fertility regulation of wild and domestic species. J Biotechnol 1999;73:91-101.

[16] Hinds LA, Hardy CM, Lawson MA, Singleton GR. Developments in fertility control for pest animal management. Aciar Mg S 2003;96:31-6.

[17] Barfield JP, Nieschlag E, Cooper TG. Fertility control in wildlife: humans as a model. Contraception 2006;73:6-22. 
[18] Millar SE, Chamow SM, Baur AW, Oliver C, Robey F, Dean J. Vaccination with a synthetic zona pellucida peptide produces long-term contraception in female mice. Science 1989;246:935-8.

[19] Gupta N, Chakrabarti K, Prakash K, Wadhwa N, Gupta T, Gupta SK. Immunogenicity and contraceptive efficacy of Escherichia coli-expressed recombinant porcine zona pellucida proteins. Am J Reprod Immunol 2013;70:139-52.

[20] Commandeur S, Lin MY, van Meijgaarden KE, Friggen AH, Franken KL, Drijfhout JW, et al. Double-and monofunctional CD4+ and CD8+ T-cell responses to Mycobacterium tuberculosis DosR antigens and peptides in long-term latently infected individuals. Eur J Immunol 2011;41:2925-36.

[21] Wickham H. ggplot2: elegant graphics for data analysis. J Stat Softw 2010;35:65-88.

[22] Team RC. R: A language and environment for statistical computing. Vienna, Austria: R Foundation for Statistical Computing; 2016. 2017.

[23] Mahi-Brown CA, McGuinness RP, Moran F. The cellular immune response to immunization with zona pellucida antigens. J Reprod Immunol 1992;21:29-46.

[24] Rath A, Batra D, Kaur R, Vrati S, Gupta SK. Characterization of immune response in mice to plasmid DNA encoding dog zona pellucida glycoprotein-3. Vaccine 2003;21:1913-23.

[25] Rhim SH, Millar SE, Robey F, Luo AM, Lou YH, Yule T, et al. Autoimmune disease of the ovary induced by a ZP3 peptide from the mouse zona pellucida. J Clin Invest 1992;89:28.

[26] Lou Y, Park K, Agersborg S, Alard P, Tung KSK. Retargeting T cell-mediated inflammation: a new perspective on autoantibody action. J Immunol 2000;164:5251-7.

[27] Banchereau J, Briere F, Caux C, Davoust J, Lebecque S, Liu Y-J, et al. Immunobiology of dendritic cells. Annu Rev Immunol 2000;18:767-811.

[28] O'Leary S, Lloyd ML, Shellam GR, Robertson SA. Immunization with recombinant murine cytomegalovirus expressing murine zona pellucida 3 causes permanent infertility in BALB/c mice due to follicle depletion and ovulation failure. Biol Reprod 2008;79:849-60.

[29] De Koker S, Fierens K, Dierendonck M, De Rycke R, Lambrecht BN, Grooten J, et al. Nanoporous polyelectrolyte vaccine microcarriers. A formulation platform for enhancing humoral and cellular immune responses. J Control Release 2014;195:99-109.

[30] Li J, Jin H, Zhang A, Li Y, Wang B, Zhang F. Enhanced contraceptive response by co-immunization of DNA and protein vaccines encoding the mouse zona pellucida 3 with minimal oophoritis in mouse ovary. J Gene Med 2007;9:1095-103.

[31] Govind CK, Srivastava N, Gupta SK. Evaluation of the immunocontraceptive potential of Escherichia coli expressed recombinant non-human primate zona pellucida glycoproteins in homologous animal model. Vaccine 2002;21:78-88. 
[32] Lea IA, Widgren EE, O'Rand MG. Analysis of recombinant mouse zona pellucida protein 2 (ZP2) constructs for immunocontraception. Vaccine 2002;20:1515-23.

[33] Joonè CJ, Schulman ML, Bertschinger HJ. Ovarian dysfunction associated with zona pellucidabased immunocontraceptive vaccines. Theriogenology 2017;89:329-37.

\section{Supplementary material}

a)

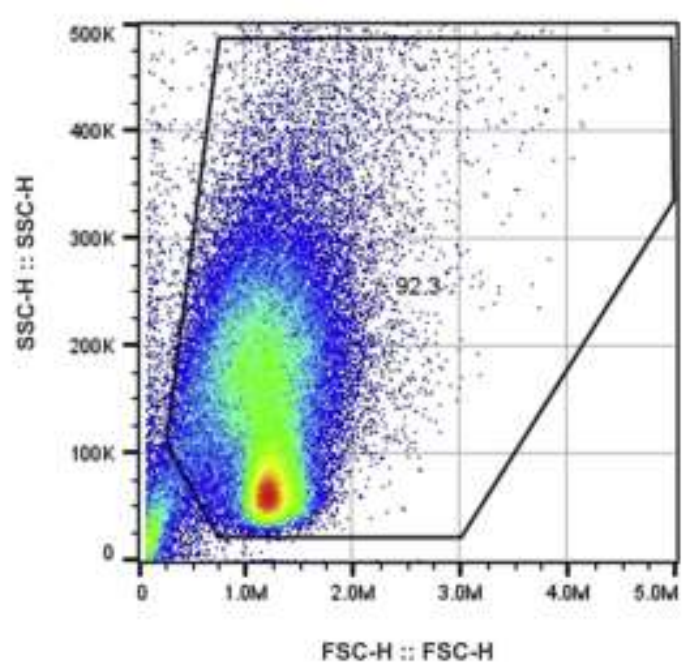

c)

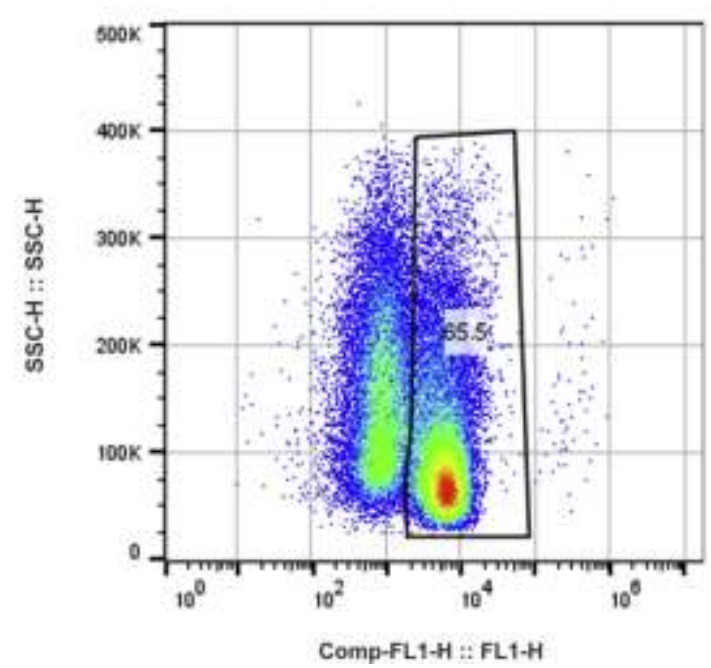

b)

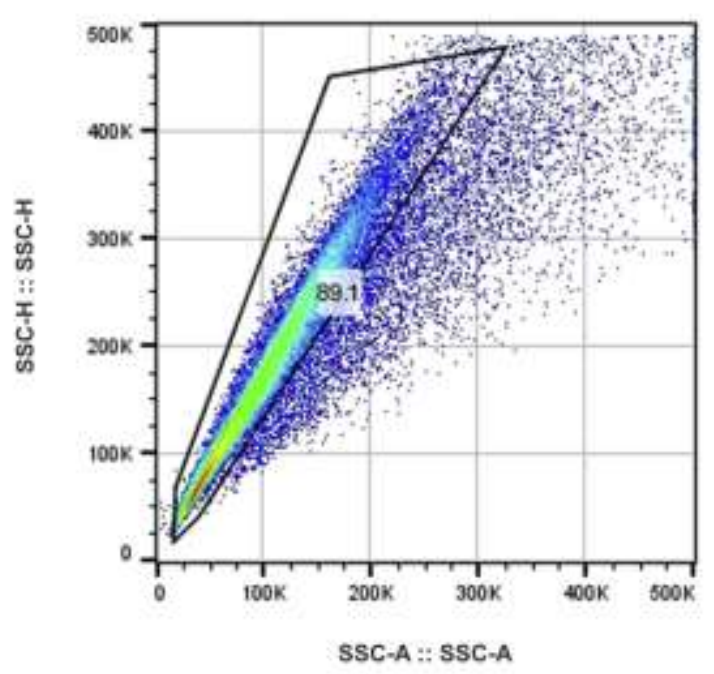

d)

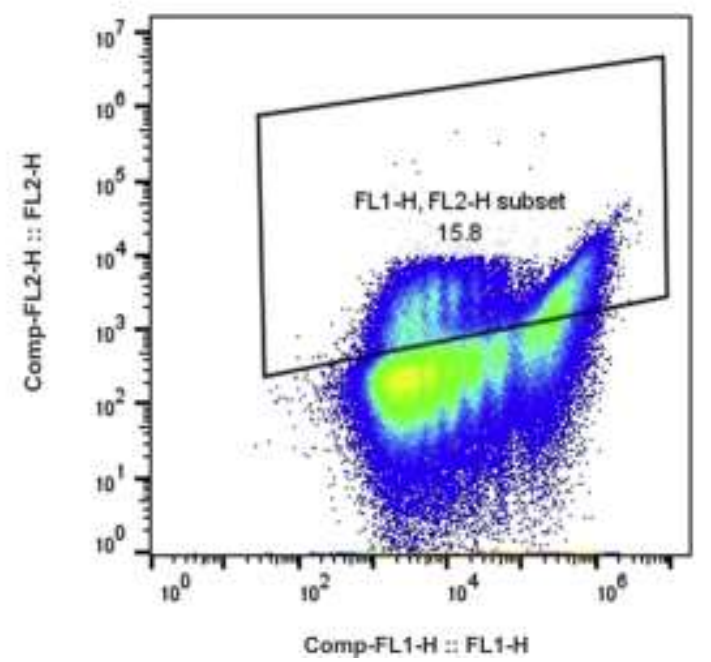

Supplementary Fig. 1. Gating strategy employed for the assessment of porcine zona pellucida antigen-specific T-cell proliferation in mares treated with pZP, recombinant pZP3 and pZP4 (reZP) or adjuvanted saline: a) debris exclusion, b) doublet exclusion c) gating of a low side scatter, $\mathrm{CD}^{+}$population and d) gating of RPEpositive (CD4 $4^{+}$or $\left.\mathrm{CD} 8^{+}\right)$events within a plot of RPE (FL2) versus CFSE (FL1). 
Supplementary Table 1. Summary of immunological measurements and reproductive data recorded in mares treated with either native pZP ( $\mathrm{n}=7$ ), recombinant pZP3 and pZP4 (reZP; $n=7$ ) or adjuvanted saline (controls; $n=7$ ), between successive timepoints pre- and post-treatment.

\begin{tabular}{|c|c|c|c|c|}
\hline \multirow[b]{2}{*}{ Variable } & \multicolumn{3}{|l|}{ Treatment group } & \multirow[b]{2}{*}{$\begin{array}{l}\mathrm{P} \\
\text { value* }\end{array}$} \\
\hline & $\begin{array}{l}\text { pZP } \\
\text { Median (range) }\end{array}$ & $\begin{array}{l}\text { reZP } \\
\text { Median (range) }\end{array}$ & $\begin{array}{l}\text { Control } \\
\text { Median (range) }\end{array}$ & \\
\hline Antibody (PP)† & $3.49^{\mathrm{a}}(2.03,3.84)$ & $0.54^{\mathrm{a}, \mathrm{b}}(0.43,1.38)$ & $-0.01^{b}(-0.04,0.02)$ & $<0.001$ \\
\hline $\mathrm{CD}^{+} \mathrm{CD}^{+} \mathrm{RP}^{+}$ & $5.1^{\mathrm{a}, \mathrm{b}}(3.6,25.1)$ & $30.7^{\mathrm{a}}(7.6,50.4)$ & $-5.8^{b}(-30.1,14.6)$ & 0.004 \\
\hline $\mathrm{CD}^{+} \mathrm{CD}^{+} \mathrm{RP}^{+}$ & $4.5^{a, b}(-1.0,29.1)$ & $18.5^{\mathrm{a}}(3.0,44.3)$ & $0.9^{b}(-4.2,6.8)$ & 0.012 \\
\hline $\mathrm{AMH}(\mathrm{ng} / \mathrm{mL}) \ddagger$ & $0.67^{\mathrm{a}}(0.31,1.66)$ & $0.40^{\mathrm{a}, \mathrm{b}}(-0.93,1.08)$ & $-0.25^{b}(-0.89,1.16)$ & 0.020 \\
\hline Oestradiol (pmol/L)§ & $4.7(2.7,30.6)$ & $3.4(0.6,20.2)$ & $3.0(-0.4,11.3)$ & 0.394 \\
\hline Progesterone $(\mathrm{nmol} / \mathrm{L}) \S$ & $8.2^{\mathrm{a}}(2.5,24.3)$ & $2.1^{\mathrm{b}}(-22.3,8.8)$ & $6.3^{a, b}(-6.1,11.1)$ & 0.039 \\
\hline Mean ovarian volume $\left(\mathrm{cm}^{3}\right) \S$ & $17.4(-8.4,39.4)$ & $-19.5(-26.2,21.2)$ & $-11.8(-42.9,51.5)$ & 0.126 \\
\hline
\end{tabular}

$\mathrm{PP}=$ proportion positive. $\mathrm{RP}=$ relative proliferation. $\mathrm{AMH}=$ anti-Müllerian hormone.

*Based on Kruskal-Wallis tests comparing values among treatment groups. Medians without superscripts in common were significantly different $(\mathrm{P}<0.05)$ after post hoc pairwise Mann-Whitney $\mathrm{U}$ tests incorporating Bonferroni correction of $\mathrm{P}$ values.

tCalculated as the measurements at day 63 or 70 minus measurements at day 0

$\ddagger$ Calculated as the measurements at day 0 minus measurements at day 105

$\S$ Calculated as the average pre-second vaccination measurements minus the average of measurements from day 63 through 105 